\title{
Yellow in Black and White: Representasi Identitas Asia oleh Rich Brian dalam Musik Hip-Hop di Amerika Serikat
}

\author{
Nokia Putri Andika Lainsyamputty | Mahasiswa Prodi Magister IImu Komunikasi, FISIPOL, UGM bisa dihubungi \\ melalui email nokia.putri.a@mail.ugm.ac.id
}

\section{ABSTRAK}

\section{Abstract}

The representation of the Asian race in the US music industry is still relatively small. However, Rich Brian, a person of Chinese descent with Indonesian nationality, succeeded in his career by carrying out the hip-hop genre that was firmly rooted in African-American (black) racial groups in the United States, a country which was dominated by Caucasian (white) races. This study aims to uncover how Brian represented his identity in the US hip-hop music scene using Stuart Hall's circuit of culture theory. The object of this research is the lyrics of several songs in Rich Brian's album. Through the analysis process, it was found that Brian did not cover the nationality and race identity he had. He precisely positioned himself on the spectrum of social identity. This then affects the representation of identity that he does in his songs, including revolving around the theme of the meaning of identity and stereotypes of the Asian race, as well as the struggles experienced by Asians who are part of minority groups in the United States.

\section{Keywords:}

\section{A. Pendahuluan}

Dekade 1990-an menjadi awal penanda meluasnya konsep globalisasi sebagai pengganti dari konsep imperialisme media (Sparks, 2007). Globalisasi merupakan penggabungan masyarakat ke dalam sebuah modernitas kapitalis yang mempercepat laju mengalirnya ide, norma, dan nilai dalam masyarakat tanpa dihalangi oleh batasan geografis dan waktu, sehingga proses komunikasi tidak lagi terkotak-kotak dan terpusat seperti gagasan imperialisme media dan budaya sebelumnya (Dirlik, 2003; Oloka-Onyango, 2005). Pertukaran ekonomi yang tadinya terbatas kepada produksi dan distribusi benda fisik, kemudian berkembang menjadi produksi dan distribusi simbol dari budaya. Tidak adanya beban material dan jarak fisik menyebabkan pertukaran simbol dari budaya ini dapat terjadi dengan cepat (Sparks, 2007). Proses globalisasi ini juga memungkinkan media untuk mengekspos berbagai macam budaya di dunia kepada masyarakat luas.

Budaya merupakan kumpulan dari simbol (Lull, 2001) yang membentuk sistem representasi dari berbagai macam konsep. Integrasi dari rangkaian ini bergantung pada kemampuan manusia sebagai bagian dari masyarakat untuk mempelajari dan meneruskan pengetahuan mengenai nilai, ide, dan kepercayaan ini pada generasi selanjutnya (Hall, 1997). Hall (1997) menyebut bahwa representasi ini awalnya berbentuk mental dan baru akan memiliki makna ketika dikomunikasikan dengan orang lain 
dalam bahasa yang sama. Bahasa yang dimaksud di sini tidak terbatas pada bahasa secara lingustik (contoh: bahasa Indonesia, bahasa Inggris), namun termasuk juga di dalamnya adalah konten gambar, musik, atau gesture tubuh.

Ketika mengacu pada definisi budaya yang sama namun dengan asosiasi "modernitas" (Hall, 1997), maka budaya tersebut dapat digolongkan kepada tingkatan budaya populer (popular culture-disingkat menjadi pop culture). Pop culture didefinisikan sebagai ekspresi atau produk dari budaya apa pun yang dapat ditemukan dengan mudah dalam sebuah populasi (Real, 2001). Sampai saat ini, produk dari pop culture masih didominasi oleh produk dari belahan dunia barat (western), terutama oleh Amerika Serikat (AS). Hal ini dikarenakan AS mulai mengembangkan strategi untuk melakukan ekspansi pengaruhnya ke seluruh dunia sejak dekade 1950an, salah satunya adalah melalui penetrasi pop culture (Chua \& Cho, 2012). Pasar media di seluruh dunia menjadi target penetrasi dan integrasi oleh korporasi media besar asal AS seperti Disney dan Time Warner (Iwabuchi, 2010). Sebagai pencerita kultural, media massa memiliki tugas untuk menjadi sumber informasi mengenai stereotype budaya yang dapat diakses dengan bebas dan luas oleh masyarakat umum. Kaum minoritas pada media massa AS sepanjang sejarah telah tidak terwakilkan dengan baik, terlabeli dengan stereotype yang berlebihan atau tidak sesuai, dan bahkan benar-benar terhapus dari media massa AS (Behm-Morawitz \& Ortiz, 2012). Dominasi produk pop culture AS dalam menembus pasar media di dunia juga mendukung dominasi representasi ras Kaukasian dibandingkan ras lainnya. Namun dibandingkan dengan ras lainnya, ras Asia tidak terepresentasikan dengan baik pada media mainstream AS. Ketika mereka tampil pun terkadang dibarengi dengan stereotype yang tidak sesuai atau berlebihan (Zhang Q., 2010).

Masalah kurangnya representasi Asia dalam media massa AS, terutama dalam industri musik, juga turut dirasakan oleh Sean Miyashiro. Hal inilah yang turut melandasinya dalam mendirikan 88 rising, sebuah perusahaan yang menggabungkan komponen manajemen, pemasaran, label rekaman, sekaligus produksi konten yang terkonsentrasi pada genre Asian hiphop (Dao, 2019). Budaya hip-hop sendiri bermula dari kelas pekerja ras Afrika-Amerika, Indian, dan Latin di South Bronx pada tahun 1970an yang biasanya memiliki elemen berupa rap dan tarian di dalam karyanya (Cordington, 2003). Kini, musik Hip-hop telah menjadi sub-kultur sekaligus genre musik yang mengglobal, bahkan untuk pertama kalinya melampaui genre rock sebagai genre musik paling populer di Amerika Serikat pada tahun 2017 (Lynch, 2018). Meskipun Miyashiro mengakui bahwa tidak mudah untuk membawa gelombang baru hip-hop bernuansa Asia ke kancah industri musik AS (Wu, 2018), namun usahanya membawakan hasil. 88rising menjadi penyelenggara festival musik Asia-sentris pertama di AS dengan tajuk Heads In The Clouds Music \& Arts Festival. Selain itu, artis di bawah naungan mereka, Rich Brian dan Joji, berhasil menempati peringkat pertama pada tangga musik Hip-hop dan RnB iTunes dan Billboard pada tahun 2018 (Dao, 2019). Keberadaan 88rising di tengah industri musik AS telah berkontribusi dalam 
mengangkat identitas Asia yang sebelumnya kurang terwakilkan.

Rich Brian, yang memiliki nama asli Brian Imannuel, merupakan seorang rapper, penyanyi, penulis lagu, sekaligus produser musik yang berasal dari Indonesia. Artis kelahiran Jakarta, 3 September 1999 ini menghabiskan masa kecilnya dengan homeschooling dan mengenal dunia melalui internet. Dari internet, Brian juga mempelajari bahasa Inggris dan memulai kariernya dengan membuat konten komedi di Twitter dan Vine. Pada Maret 2016, Brian mengunggah debut singlenya di Soundcloud yang berjudul "Dat \$tick". la turut mengunggah video klip dari lagu tersebut di Youtube. Lagu ini kemudian menuai popularitas internasional dan menjadi awal mula melejitnya karir Brian di dunia industri musik (Wong, 2018). Pada tahun 2017, Brian bergabung dengan label 88rising dan telah merilis dua full album serta 9 single sampai saat ini.

Rich Brian tidak menutup-nutupi identitas ras dan etnis yang ada pada dirinya. la sendiri merupakan keturunan etnis Tionghoa yang lahir dan dibesarkan di Indonesia. Rich Brian mengungkapkan identitasnya tersebut baik melalui lagu dan musik yang ia produksi atau melalui konten di media sosialnya. Dalam lagulagu yang ia produksi, Brian tidak jarang menyertakan referensi yang merujuk kepada identitasnya sebagai keturunan Asia. Misalnya pada lagu Yellow yang ia rilis tahun 2019, menceritakan tentang tantangan yang ia hadapi sebagai seorang keturunan Asia yang hidup dan berkarir di Amerika Serikat-sebuah negara dengan kultur yang sangat berbeda dengan Asia.
Melalui akun Instagram (@brianimanuel) dan akun Twitter (@richbrian), ia juga tidak jarang membuat konten yang menunjukkan identitasnya sebagai warga negara Indonesia. Brian juga turut mewakili musisi Indonesia dalam acara festival seni kreatif dan teknologi terbesar dunia, South by Southwest (SXSW) 2018 yang berlangsung dari 918 Maret 2018 di Austin, Texas, Amerika Serikat (Saputri, 2018).

Musik hip-hop yang diasosiasikan dengan ras Afrika-Amerika (black) merupakan genre musik paling populer saat ini di kalangan masyarakat Amerika yang didominasi oleh ras kaukasian (white). Namun Rich Brian, seorang yang tidak berasal dari kedua ras tersebut, berhasil membuat musik dengan genre hip-hop yang membuat namanya melejit di Amerika Serikat. Rich Brian merupakan artis Asia pertama yang menduduki peringkat 1 pada tangga lagu Hip-Hop di iTunes dengan album debutnya yang berjudul Amen tahun 2018 (Dao, 2019). Hal ini menandakan adanya penerimaan yang positif terhadap karya Brian tanpa memandang identitas ras Asia yang selain melekat pada diri Brian, juga memengaruhi mempengaruhi karya-karya yang ia buat.

Atas pemaparan tersebut, penulis kemudian memutuskan untuk mengeksplorasi lebih dalam mengenai representasi identitas Asia yang dilakukan oleh Rich Brian sebagai musisi hiphop yang berkarier di Amerika Serikat. Peneliti ingin mendalami tentang bagaimana cara Brian merepresentasikan identitas ras dan etnisnya selain melalui karya yang ia buat, juga melalui bagaimana Brian merepresentasikan dirinya sebagai individu kepada khalayak luas. 


\section{Tinjauan Pustaka}

Penulis menemukan dua penelitian dengan konteks dan substansi serupa. Penelitian yang dilakukan oleh Dasfriana (2019) menggunakan sudut pandang korporasi (dalam hal ini 88Rising) untuk mengeksplorasi dampak komodifikasi budaya yang dilakukan 88Rising dalam rangka menjembatani cultural boundary antara budaya barat dan timur. Genre Asian Hip-Hop yang diusung oleh 88Rising adalah budaya populer yang menjadi mediumnya. Penelitian lainnya dilakukan oleh Andrew (2018) dan berfokus pada image Rich Brian sebagai seorang rapper kelas internasional. Penelitian yang dilakukan oleh Dasfriana melihat dari sisi korporasi media (88Rising), sementara penelitian yang dilakukan oleh Andrew meninjau identitas Brian sebagai seorang artis. Penulis ingin mengisi celah diantara penelitian-penelitian tersebut dengan mengeksplorasi bagaimana Rich Brian merepresentasikan identitas Asianya dalam skena musik hip-hop di Amerika Serikat.

\section{Circuit of Culture -Stuart Hall}

Penelitian ini menggunakan teori Circuit of Culture $(\mathrm{CoC})$ yang digagas oleh Stuart Hall. Menurut Hall (1997), budaya adalah persoalan makna bersama. Oleh karena itu teori ini berusaha untuk menjelaskan bagaimana sebuah makna dikonstruksi dari 5 tahap: representasi, produksi, konsumsi, identitas, dan regulasi. Meskipun dalam bagan kelima tahap ini digambarkan terpisah, namun pada kenyataannya lima tahap ini akan mengalami overlap dan berinteraksi satu sama lain dalam cara yang kompleks (du Gay, Hall,
Janes, Mackay, \& Negus, 1997). Teori CoC dikembangkan untuk menggambarkan bagaimana makna dibentuk dan disebarkan dalam dan antar budaya. Sirkulasi dari makna yang stabil dan masuk akal (atau konstruksi dari kebenaran) akan membantu terjadinya regulasi dan kontrol. Sementara untuk menjamin identitas dan sense of un/belonging, pola konsumsi dan apropriasi akan menyediakan nilai menuju makna yang lebih disukai (Leve, 2012).

\section{Representasi}

Hall (1997) mendefinisikan representasi sebagai praktik pengonstruksian makna melalui penggunaan tanda dan bahasa. Seseorang memberikan makna pada suatu hal dari b a g a i m a o r a ng tersebut merepresentasikannya. Sekumpulan makna yang kemudian menyusun sebuah budaya adalah hal yang terlibat dalam seluruh lapisan masyarakat dan tidak bisa direduksi secara sederhana menjadi sesuatu yang genetik atau diturunkan. Budaya adalah hal yang membedakan elemen manusia dari sekedar keinginan biologis dalam kehidupan sosial (Hall, 1997). Teks adalah medium dari budaya yang dapat digunakan untuk menelaah proses representasi pada sirkuit budaya (O'Reilly, 2010). Karena gambar, suara, dan objek termasuk ke dalam sistem tanda yang memiliki mekanisme serupa seperti bahasa, maka kita dapat merujuk hal-hal tersebut sebagai cultural texts (teks kultural)(Barker, 2000). 


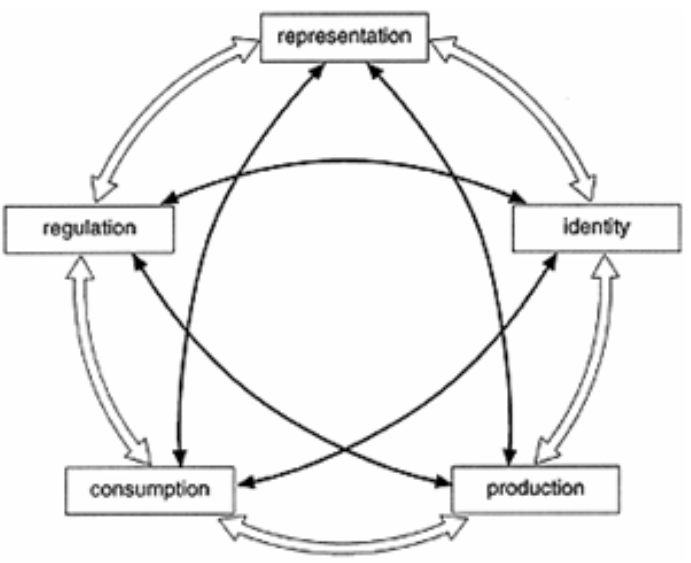

Gambar 1. Bagan Circuit of Culture yang digagas oleh Hall $(1997$, p.1)

Konsep mengenai representasi ini salah satunya dipengaruhi oleh gagasan dari Ferdinand de Saussure, seorang ahli bahasa asal Swiss, dengan fokus utamanya yaitu pembentukan makna melalui bahasa sebagai sistem tanda. Bahasa yang dimaksud mencakup pada suara, gambar, teks, atau karya seni lainnya. Saussure membagi tanda menjadi dua elemen: signifier (penanda) dan signified (petanda). Penanda adalah bentuk asli dari bahasa yang memiliki makna (kata-kata dalam bahasa tertentu, gambar, foto, dan sebagainya). Sementara petanda adalah gagasan atau konsep mental yang diasosiasikan dengan bahasa tersebut. Saussure lebih lanjut memaparkan bahwa relasi antara penanda dan petanda yang ditetapkan oleh kode budaya kita tidak bersifat tetap secara permanen. Kata-kata akan mengalami perubahan makna. Konsepkonsep (petanda) yang menjadi rujukan juga akan berubah. Jika hubungan antara penanda dan petanda adalah hasil dari sistem adat sosial yang spesifik untuk setiap masyarakat dan momenmomen historis tertentu, maka semua makna dihasilkan dalam sejarah dan budaya. Maknamakna ini tidak bersifat tetap secara permanen, tetapi akan selalu dapat berubah, baik dari satu konteks budaya dan dari satu periode ke periode lainnya. Dengan demikian tidak ada 'makna sebenarnya' yang universal, tunggal, dan tidak berubah (Hall, 1997).

\section{Produksi dan konsumsi}

Dikemukakan oleh du Gay dalam Hall (1997), makna diproduksi oleh media yang bervariasi, terutama pada masa modern di mana media massa merupakan sarana dari komunikasi global. Dengan teknologi yang kompleks, media massa telah mendukung sirkulasi makna antara budaya yang berbeda. Mackay dalam Hall (1997) menyebut produksi makna terjadi setiap kali seseorang mengekspresikan dirinya dengan menggunakan atau mengonsumsi hal-hal kultural yang diproyeksikan dalam ritual dan praktik kehidupan sehari-hari. Sementara, konsep mengenai konsumsi pada awalnya ditentukan oleh logika produksi dalam kapitalisme, yang memandang konsumsi adalah proses yang pasif. Keinginan dan kebutuhan konsumen dianggap merupakan hasil bentukan dari produser semata. Padahal, fokus kepada proses pemahaman mengenai konsumsi akan membantu kita untuk memahami bahwa makna tidaklah sesederhana dikirim oleh produsen dan diterima oleh konsumen, namun selalu dibentuk untuk penggunaan tertentu (du Gay, Hall, Janes, Mackay, \& Negus, 1997). Karena makna tidak berada dalam suatu objek tetapi dalam bagaimana objek itu digunakan, makna yang 
dikodekan selama produksi hanyalah satu set yang dapat diartikulasikan melalui konsumsi (Curtin \& Gaither, 2005).

Makna juga meregulasi perilaku manusia melalui pengukuhan aturan, norma, dan kebiasaan dari penataan kehidupan sosial (Thompson dalam Hall, 1997). Tahapan regulasi mencakup level analitik pada individu, organisasi, dan nasional karena sifatnya sebagai kontrol formal dari kebijakan budaya sekaligus kontrol informal dari politik budaya (Curtin \& Gaither, 2005).

\section{Identitas}

Identitas adalah makna yang diberikan kepada objek atau kelompok tertentu melalui proses produksi dan konsumsi (Woodward, 1997). Pada model CoC, publik dipahami dalam istilah relasional yang lebih dinamis, sebagai individu yang dikelompokkan secara longgar yang secara aktif menegosiasikan berbagai jenis identitas (Curtin \& Gaither, 2005). Tajfel \& Turner (dalam Baron \& Branscombe, 2012) melalui teori identitas sosial, mengemukakan bahwa seseorang bisa memandang dirinya secara berbeda pada saat tertentu, tergantung di mana mereka berada antara kontinum identitas pribadi versus identitas sosial. Pada ujung dari kontinum personal, seseorang akan menganggap dirinya sebagian besar sebagai individu. Pada ujung dari kontinum sosial, seseorang menganggap dirinya sebagai anggota kelompok sosial tertentu. Seseorang tidak mengalami semua aspek konsep diri secara bersamaan, tergantung di bagian kontinum mana mereka menempatkan diri mereka. Ini akan mempengaruhi cara mereka berpikir tentang dirinya sendiri. Bagian dari identitas yang saat itu menjadi fokus perhatian seseorang akan mempengaruhi bagaimana mereka memandang diri mereka sendiri dan merespons orang lain.

Dalam model CoC oleh Stuart Hall, praktik penandaan (periklanan, internet, musik populer, film, dan televisi) diproduksi dan didorong ke masyarakat melalui teknologi dan media. Model CoC memungkinkan terjadinya pengenalan kekuasaan, budaya dan identitas, serta sifat cair dari konstruksi makna, tanpa mengistimewakan perspektif teoritis Barat yang dominan. Model ini pun akan relevan dan berguna jika digunakan dalam konteks komunikasi lintas budaya, ditambah dengan semakin berkembangnya komunikasi digital pada masa kini yang memungkinkan terjadinya pertukaran pesan dengan lebih cepat (Childs, 2015; Tombleson \& Wolf, 2017).

Dengan demikian, pertanyaan tentang makna muncul dalam kaitannya pada seluruh tahapan yang berbeda dalam "sirkuit budaya": dalam konstruksi identitas dan penandaan perbedaan, dalam produksi dan konsumsi, serta dalam regulasi perilaku sosial (Hall, 1997). Lima proses yang saling terkait ini kemudian memiliki implikasi pada produksi dan sirkulasi makna melalui bahasa (Leve, 2012). Dari kelima tahap dalam sirkuit budaya, penelitian ini akan membatasi fokus kepada tahapan representasi dan identitas. 


\section{Metode Penelitian}

Subjek dari penelitian ini adalah lirik lagu dalam album milik Rich Brian. Mempelajari cara seseorang berpikir dan menyampaikan gagasannya dapat dilihat dari bagaimana cara individu tersebut menggunakan bahasa (Lightman, McCarthy, Dufty, \& McNamara, 2007). Dalam budaya populer, ini bisa dilihat dari lirik lagu yang diciptakan oleh seorang artis. Jika diiringi dengan kata-kata, lagu memungkinkan seseorang untuk mengkomunikasikan emosi, bercerita, dan bahkan mengungkapkan pendapat dan sikap mereka. Lirik lagu menceritakan kisah dan berkomunikasi dengan audiens dengan cara yang mirip dengan cara orang melakukan percakapan satu sama lain (Pettijohn \& Sacco Jr, 2009). Rich Brian berkontribusi pada penulisan lirik seluruh lagu dari album Amen yang dirilis tahun 2018 dan album The Sailor yang dirilis tahun 2019, baik sebagai penulis tunggal maupun bekerja sama dengan artis lainnya. Ini menjadi bukti bahwa lagulagu di albumnya merupakan cara Brian untuk mengkomunikasikan kisah, emosi, maupun pengalaman yang ia alami sendiri. Penentuan sampel yang akan digunakan didasari pada tujuan penelitian dan aspek representasi dan identitas dari teori circuit of culture. Maka, kategori pemilihan sampel lirik lagu yang akan diteliti adalah:

Penyebutan eksplisit kata Indonesia atau Asia

- Penyebutan implisit dari Indonesia atau Asia, mengacu pada perumpamaan, simbol, atau stereotip yang menyangkut Indonesia ataupun Asia.
Sampel yang kemudian dijadikan subjek untuk diteliti adalah lima lagu dari album Amen: Amen, Occupied, Arizona, Flight, dan Enemies; serta tiga lagu dari album The Sailor: The Sailor, Yellow, dan Kids. Subjek penelitian yang berupa lirik lagu ini merupakan manifestasi dari apa yang disebut Hall (1997) sebagai cultural text yang berperan untuk mengonstruksi makna.

Dalam penelitian ini, penulis menggunakan metode analisis isi kualitatif. Analisis isi kualitatif adalah metode yang lebih dari sekadar menghitung kata atau mengekstraksi konten objektif dari teks. Metode memungkinkan peneliti untuk memahami realitas sosial secara subjektif tetapi ilmiah, dengan memeriksa makna, tema, dan pola yang mungkin terwujud atau terpendam dalam teks tertentu (Zhang \& Wildemuth, 2017). Pendekatan kualitatif memungkinkan munculnya tema dari data selama proses analisis karena kerangka kerja pengkodean terus dibentuk oleh informasi yang muncul. Analisis isi kualitatif membutuhkan sampel yang relatif kecil dan dipilih secara purposif. Hasilnya adalah deskripsi tekstual, tipologi, dan model deskriptif(Spurgin \& Wildemuth, 2017). Tahapan dalam melakukan penelitian ini dimulai dengan mendengarkan lagulagu yang telah dipilih menjadi subjek penelitian dan membaca liriknya secara bersamaan. Kemudian, peneliti menyoroti potongan lirik yang mengindikasikan penyebutan eksplisit maupun implisit dari identitas Asia maupun Indonesia. Potongan-potongan lirik tersebut kemudian diinterpretasi untuk dapat melihat tema-tema apa saja yang muncul. Tema-tema yang serupa atau berhubungan akan dikelompokkan pada satu 
tema yang lebih besar lagi. Untuk menambah keakuratan dari terjemahan dan interpretasi subjek penelitian, peneliti melakukan peer review dengan expert lain berinisal SI yang memiliki latar belakang pendidikan Sastra Inggris.

Representasi Identitas Brian sebagai Orang Indonesia

Dari seluruh lagu di seluruh album dan EP yang pernah Rich Brian rilis, ia beberapa kali menyebutkan tentang Indonesia sebagai negara tempat ia berasal. Penyebutan itu ia lakukan baik secara implisit maupun secara eksplisit. Penyebutan Indonesia secara eksplisit terdapat pada lagu Arizona:

People wonderin' where in the fuck is Indo

Dan pada lagu Kids:

Victorious tropical flow comin' straight from Indo' These plants only grow to just get cut and disposed

Jika dilihat dari perspektif orang Amerika, Lowe dalam Reyes (2017) menyatakan bahwa menjadi sebuah tantangan bagi mereka untuk mengidentifikasi kesatuan identitas kelompok Asia-Amerika karena beragamnya kelompok etnis di Asia. Ditambah dengan rasa tidak familiar dengan negara-negara di Asia Tenggara, orang Amerika sulit untuk mengidentifikasi orang Asia secara akurat berdasarkan negara asal mereka. Ini pun tercermin dari pertanyaan tentang di mana letak negara Indonesia, pada lirik lagu Arizona tersebut. Pada lirik lagu Kids, Brian membawa kata "tropical" untuk menunjukkan asosiasi dengan Indonesia sebagai negara tropis di Asia Tenggara, dan kalimat "These plants only grow to just get cut and disposed" untuk menunjukkan permasalahan penebangan hutan yang dihadapi oleh Indonesia.

Meskipun Brian tidak menutup-nutupi identitasnya sebagai warga negara Indonesia, ia juga pernah mendapatkan tudingan bahwa ia telah melupakan tempat asalnya. Tudingan ini dilontarkan karena Brian memilih untuk berkarier di luar negeri dibandingkan di negara asalnya sendiri. Melalui wawancara dengan The Guardian (Herd, 2016), Brian mengungkapkan bahwa jenis musik hip-hop dan rap adalah genre musik yang minoritas di Indonesia. Tidak hanya jenis musik, namun Brian sendiri sebagai keturunan etnis Tionghoa merupakan bagian dari kelompok minoritas di Indonesia. Data dari Badan Pusat Statistik (2010) menunjukkan bahwa hanya penduduk Indonesia keturunan Tionghoa hanya berjumlah 1,2\% dari total populasi. Posisi Brian sebagai kelompok minoritas di Indonesia dan musik hip-hop yang tidak mendapat porsi perhatian lebih di Indonesia pun menjadi alasan Brian lebih memilih Amerika Serikat sebagai tempat berkariernya. Selain itu, Brian juga mengakui secara terus terang bahwa caranya merepresentasikan Indonesia di mata internasional adalah dengan terus melakukan hal yang ia sukai, yaitu bermusik (Agato, 2019). Tudingan yang Brian dapatkan itu ia ungkapkan dalam lagu Amen, di mana Dory yang ia rujuk pada lirik ini adalah tokoh fiksi dari film Finding Nemo yang memiliki sifat pelupa. People think I'm Dory, I'm forgettin' 'bout my
hood

Man, should I be sorry for just doin' somethin'new? 
Sementara pengungkapan identitasnya secara implisit Brian ungkapkan pada lagu Occupied:

Red and white, born and raised, took a flight, to LA

Pada lagu Flight:

Gettin' ready for this life, all I see is red and white

Dan pada lagu Enemies:

Reppin' red and white so hard I barely can control it

Kata "reppin" yang dimaksud dalam penggalan lirik tersebut merupakan bentuk informal dari kata representing yang bermakna "mewakili". Brian menggunakan kata red and white untuk menyimbolkan Indonesia secara implisit karena kedua warna tersebut merupakan warna bendera negara Indonesia.

Dikemukakan oleh Hall (1997), pemikiran dan perasaan seseorang merupakan bagian dari sistem representasi. Budaya yang mengelilingi seseorang akan memiliki kode yang mempengaruhi bagaimana seseorang bisa berpikir dan merasakan tentang dunia. Sehingga orang-orang merupakan anggota dari budaya yang sama akan menafsirkan dunia di sekitarnya menggunakan cara yang relatif mirip. Dari lirik lagunya, Brian menyebutkan identitasnya sebagai orang Indonesia baik secara eksplisit menyebutkan kata Indonesia maupun secara implisit menggunakan perantara warna bendera Indonesia yaitu merah dan putih-red and white.

Oleh Schatz \& Lavine (2007) bendera sebuah negara merupakan sebuah simbol nasional, di mana simbol nasional ini dapat menimbulkan sentimen yang kuat dan emosional.
Hal ini disebabkan karena simbol nasional berperan sebagai penanda (signifier) dari identitas individu sebagai anggota sebuah negara. Simbol nasional seperti bendera merupakan representasi manifes dari sebuah kelompok yang memberikan anggota kelompok sebuah objek identifikasi yang nyata. Akibatnya, simbol nasional, dalam hal ini bendera, mewakili kelompok secara keseluruhan dalam mengkomunikasikan batasan antara ingroup dan outgroup (Schatz \& Lavine, 2007). Melalui lirik yang ia tulis mengenai Indonesia secara implisit, Brian ingin mengungkapkan bahwa ia adalah seorang individu yang menjadi bagian dari sebuah kelompok, dalam hal ini adalah negara, yaitu Indonesia. Dalam hal ini, warna bendera Indonesia merupakan sebuah penanda visual yang memiliki konsep sebagai simbol nasional sekaligus kode budaya yang Brian bawa untuk menunjukkan identitasnya.

\section{Menjadi Orang Asia di Amerika Serikat}

Secara umum, ada dua jenis stereotip orang Asia yang dibentuk oleh masyarakat barat, yaitu: yellow face/skin (berkulit kuning) dan model minority (minoritas teladan). Stereotip yellow skin berasal dari gagasan yellow peril (bahaya kuning), yang merupakan stereotip ras yang berasal dari negara Barat pada awal abad 20. Saat itu, Tiongkok dan Jepang mengalami kebangkitan dari sisi populasi dan kekuatan politik. Negara-negara Barat menganggap itu sebagai ancaman dari ras kulit kuning terhadap ras kulit putih. Kehadiran wajah-wajah "oriental" di Amerika Serikat pun membangkitkan kekhawatiran di kalangan ras 
kulit putih. Sementara stereotip minoritas teladan mulai muncul pada dekade 1960-an yang menggambarkan kelompok Asia sebagai orang yang dekat dengan keluarga, serius tentang pendidikan, dan taat hukum. Model minoritas teladan adalah konstitutif dari ideologi colorblind dalam arti bahwa "kesuksesan" orang AsiaAmerika digunakan untuk menyangkal keberadaan rasisme institusional dan untuk "membuktikan" bahwa masyarakat Amerika cukup adil dan terbuka bagi kelompok minoritas ras untuk meningkatkan status sosial (Kawai, 2005).

Brian pernah menuai kontroversi akibat nama panggung yang pernah ia gunakan, yaitu Rich Chigga. "Chigga” merupakan gabungan dari Chinese dan "nigger", bertujuan untuk mengasimilasi identitas Brian sebagai keturunan Tiongkok dan musik hip-hop yang mengakar pada budaya orang kulit hitam di Amerika. Namun, kata "nigger" yang berarti "orang kulit hitam" dalam bahasa Spanyol umumnya dianggap ofensif bagi orang kulit hitam tidak hanya karena istilah tersebut membedakan mereka berdasarkan warna kulit mereka, tetapi juga karena istilah tersebut membawa konotasi perbudakan, inferioritas dan penindasan (van der Meer, 2008). Pada 1 Januari 2018, melalui seluruh media sosialnya, Brian mengumumkan bahwa ia akan mengganti nama panggungnya menjadi Rich Brian. Melalui wawancara dengan Billboard (Geeting, 2018) Brian menyatakan bahwa setelah ia pindah ke Amerika Serikat Juli 2017 lalu untuk bergabung dengan label 88Rising, ia ingin membuat sebuah perubahan dan berharap karyanya akan membawanya menuju kesuksesan.
Belajar dari kesalahannya, Brian memutuskan untuk merepresentasikan identitas ras dan yang melekat pada dirinya dengan lebih baik. Melalui wawancara dengan complex.com, bagi Brian album The Sailor-dalam bahasa Indonesia memiliki arti "pelaut" - juga dapat bermakna sebagai sebuah metafora bagi para imigran yang tiba ke Amerika Serikat untuk mendapatkan hidup yang lebih layak, termasuk kelompok Asia-Amerika. Lagu Yellow yang ia usung sebagai lagu utama dalam album The Sailor Brian ciptakan untuk memberi tahu orang Asia lainnya bahwa meskipun belum banyak diantara mereka yang bisa mengejar impiannya, mereka tetap dapat melakukan apa yang mereka inginkan (Diep, 2019). How do I disappear without anybody knowing? Will anybody even miss me when I'm gone? Bottle full of liquor, I'ma drown tonight I can't remember when I last felt alive

Don't try to save my life, I'm already on my way tonight

The blood is on my hands, it's either do or die Don't even try to save my life (Save my life)

Lirik lagu di atas merupakan bagian awal dari lagu Yellow yang memiliki melodi mellow dan lambat. Brian menyuarakan perasaan tertekan, frustrasi, dan putus asa yang ia rasakan. la dikelilingi oleh pikiran ingin mengakhiri hidupnya. Pikiran dan perasaan itu ia simbolisasikan melalui lirik lagu yang menggambarkan upaya mengakhiri dirinya sendiri seperti dengan menenggak sebotol minuman keras dan melukai diri. la juga tidak ingin tidak ada orang yang menghalangi upayanya tersebut. Melalui lirik ini, Brian menunjukkan sisi rapuhnya sebagai seorang remaja berusia 17 tahun yang memulai hidup di sebuah benua baru 
yang memiliki budaya jauh dari tempat asalnya.

Namun pada bagian selanjutnya di lagu Yellow, Brian memutuskan untuk berubah. Nada dari lirik lagu pada bagian ini pun berubah menjadi lebih bersemangat dengan tempo yang lebih cepat.

Don't fight the feeling 'cause I'm yellow

Will I make it? Who the hell knows?

You want my soul but we don't sell those

Pada kalimat pertama di atas Brian menantang orang-orang untuk tidak merendahkan dirinya karena identitas ras yang melekat pada dirinya. Meskipun Brian sendiri sempat ragu dengan keputusannya, namun Brian memilih untuk tetap maju. la ingin terus membuat musik yang sesuai dengan passion yang ia miliki, bukan sekadar untuk memenuhi ekspektasi dari industri musik. Hidup sebagai ras minoritas di Amerika Serikat juga tidak bisa dilepaskan dari isu mengenai rasisme. Brian secara implisit menyatakan masalah ini melalui sepenggal lirik di lagu The Sailor:

Went outside and felt the breeze

A young girl walked up the street, came up right next to me

She looked me up and down with curiosity

Like I was standin' there, but not where I was supposed to be

She cracked a smile and said, "Open your eye"

"Uh, uh, what the fuck are you talkin' about? I can seejust fine"

Ini terkait dengan stereotip fisik dari orang Asia, terutama Asia Timur, yang memiliki mata sipit. Brian merupakan keturunan etnis Tionghoa yang juga memiliki mata sipit. Oleh karena itu, dalam lirik ini Brian secara implisit menunjukkan rasisme yang dilakukan oleh seorang anak perempuan yang mengatakan "Open your eye" kepadanya. Rasisme ini mungkin tidak disadari oleh anak perempuan tersebut karena usianya yang masih kecil. Selain itu, anak tersebut memandang Brian dengan rasa penasaran karena Brian memiliki fisik yang berbeda dengan dirinya.

Kim (1999) mengenalkan model racial triangulation (triangulasi rasial) untuk menjelaskan posisi ras Asia sebagai salah satu kelompok minoritas di Amerika Serikat dibandingkan dengan orang kulit putih dan orang kulit hitam. Model ini menyatakan bahwa terdapat dua proses dalam mencapai triangulasi rasial: relative valorization (penilaian status relatif) dimana ras Kaukasian sebagai ras yang dominan menilai orang Asia lebih unggul daripada orang kulit hitam pada beberapa aspek, namun pada saat yang bersamaan, orang Asia juga dikucilkan oleh ras Kaukasian (civic ostracism). Xu \& Lee (2013) melakukan penelitian yang didasari mode triangulasi rasial ini dan mengonfirmasi aspek multidimensionalitas karena adanya pergeseran penempatan orang-orang Asia-Amerika dari tinggi ke rendah ketika beralih dari penilaian status ke pengucilan sipil. Stereotip model minoritas yang melekat pada orang Asia menyebabkan mereka seringkali disamakan posisinya dengan orang kulit putih, namun sejarah opresi terhadap kelompok ini menempatkan mereka pada posisi yang sama dengan orang kulit hitam (Chang, 2013). Ketimpangan rasial ini menjelaskan inkonsistensi posisi kelompok Asia di Amerika Serikat dibandingkan dengan ras kaukasian maupun orang kulit hitam, yang kemudian Brian utarakan melalui lagu-lagu ciptaannya. 


\section{Menginspirasi Orang Asia Lainnya}

Perjalanan Brian sejak 2017 hingga saat ini telah membawa Brian kepada kesuksesan. Mendalami karier di dunia musik dan pergi ke Amerika Serikat merupakan mimpi Brian yang sudah tercapai. Rich Brian merupakan artis Asia pertama yang bisa menduduki peringkat 1 iTunes pada tangga musik hip-hop pada tahun 2018 lalu. Melalui wawancara dengan complex.com (Diep, 2019), kesuksesan ini membuat Brian sadar bahwa tidak semua orang memiliki keberanian untuk mewujudkan mimpinya seperti yang Brian lakukan, terutama bagi orang-orang yang tidak mendapat dukungan yang sama seperti dirinya. Karena itu, Brian ingin menginspirasi orang lain untuk bermimpi setinggi-tingginya. Khususnya bagi orang dari kelompok ras Asia yang menjadi minoritas dan kurang terepresentasikan, karena Brian sendiri juga merupakan keturunan ras Asia. Seperti yang ia tuliskan di lagu Yellow: Rock 50 stages in all 50 states, bitch I did it all without no citizenship To show the whole world you just got to imagine

"50 stages in all 50 states" memiliki makna bahwa Brian telah berhasil mengadakan konser di seluruh negara bagian di Amerika Serikat meskipun ia tidak mengantongi kewarganegaraan AS. la menekankan pentingnya memiliki mimpi untuk menunjukkan kepada dunia mengenai diri kita. Motivasi Brian untuk menggapai mimpinya ia ungkapkan pada penggalan lirik lagu Amen:

Do the shit for the people that look like me So the girls can see them and they think of me And not that kid that throw that fit 'Cause he didn't get straight $A$ 's all week

Kalimat pertama penggalan tersebut dapat dimaknai lebih luas jika dihubungkan dengan kalimat-kalimat selanjutnya. Brian mengungkapkan motivasinya menggapai mimpinya adalah demi mewakili dan memberikan harapan pada orang Asia lainnya yang juga memiliki mimpi besar seperti dirinya. Straight $A$ bermakna memiliki nilai sempurna secara akademik. Frasa "That kid that throw a fit cause he didn't get straight A's all week" merupakan bagian dari stereotip minoritas teladan yang melabeli orang Asia sebagai orang yang biasanya sangat serius dengan pendidikan mereka dan akan marah jika nilai mereka tidak sempurna. Brian menolak diasosiasikan dengan stereotip minoritas teladan tersebut. Kehidupan personal Brian sendiri juga bertentangan dengan stereotip itu karena ia bahkan tidak menempuh pendidikan hingga tingkat universitas. Pilihan Brian untuk memotivasi orang Asia yang memiliki mimpi tinggi dibandingkan dengan anak Asia yang marah karena tidak mendapat nilai sempurna juga dapat dimaknai sebagai usaha Brian untuk mematahkan stereotip minoritas teladan yang melekat pada orang Asia umumnya.

Pada lagu Arizona, Brian juga mengungkapkan gagasan serupa:

I'm the one and only

But I swear about a thousand Indonesian kids will come with me

Brian ingin mengatakan kepada anak-anak Indonesia lainnya bahwa baik dirinya maupun mereka sama-sama memiliki impian yang besar. Karier yang Brian bangun di skena musik internasional ini ia harapkan menjadi gerbang awal untuk menginspirasi anak-anak Indonesia lainnya dalam mencapai impian mereka.

Tema memotivasi orang-orang yang memiliki ras yang sama dengan dirinya juga 
diungkapkan secara lebih tegas oleh Brian pada lagu Kids:

I used to be the kid, now the kids wanna be me

Fuck bein' one the greatest, I'm tryna be the greatestone

I'm makin' songs that'll probably outlive us for generations

Started off as the sailor, look at me, now I'm the captain

I won't lie, this shit is fun

Tell these Asian kids they could do what they want

Might steal the mic at the GRAMMYs just to say we won

That everyone can make it, don't matter where you from

Pada lirik ini, Brian membandingkan antara dirinya dahulu sebelum memutuskan untuk mewujudkan mimpinya dengan sekarang, ketika ia sudah berhasil mencapai mimpinya. Brian memosisikan dirinya sebagai "kapten" yang menginspirasi anak Asia lainnya dalam menggapai mimpi mereka. la ingin orang lain bermimpi setinggi-tingginya dan tidak membatasi diri mereka berdasarkan identitas ras yang mereka miliki. Makna bermimpi setinggi-tingginya ini ditunjukkan oleh Brian melalui lirik "Might steal the mic at the GRAMMYs just to say we won", di mana Grammy Awards merupakan ajang penghargaan paling bergengsi di industri musik. Lagu-lagu yang Brian ciptakan ia harap bisa hidup sampai ke generasi berikutnya sebagai bukti bahwa dirinya adalah pelopor dari kelompok minoritas yang sukses berkarier di tengah kelompok mayoritas. Makna serupa juga ia tunjukkan pada penggalan lirik lagu Kids selanjutnya,

You want the blueprint for impossible, I'll let it show
Istilah "blueprint" yang berarti desain atau rancangan awal biasanya digunakan dalam konteks arsitektur, namun jika dibawa ke dalam konteks lagu ini, kata blueprint dapat bermakna sebagai pelopor atau inisiator.

Remember when Pac said, "The concrete grows a rose"

Ini merujuk kepada lirik lagu dan judul album The Rose That Grow from Concrete dari rapper kenamaan asal Amerika Serikat, Tupac Shakur. Metafora ini jika diterjemahkan secara harfiah memiliki arti bahwa beton bisa menumbuhkan mawar. Hal ini terdengar tidak mungkin, karena beton bukanlah tempat yang bisa menumbuhkan makhluk hidup. Bila mawar dianalogikan sebagai manusia, maka metafora ini bermakna bahwa ketika manusia bisa tumbuh dan mencapai versi terbaik dirinya meskipun lingkungan sekitarnya hampir tidak memungkinkannya untuk tumbuh, maka manusia tersebut telah melalui berbagai macam kesulitan hingga perlu mendapat apresiasi. Brian ingin membawa pesan bahwa seburuk apapun lingkungan yang mengelilinginya, karena ia memiliki mimpi dan harapan, ia bisa berkembang menjadi versi diri yang ingin ia wujudkan.

\section{Representasi dan Identitas}

Rich Brian merupakan seorang musisi keturunan Tionghoa yang berkewarganegaraan Indonesia. la hidup dan tumbuh dikelilingi oleh kebudayaan Indonesia, namun di sisi lain juga terpapar unsur-unsur budaya asing yang ia dapatkan melalui internet. Sekarang, Brian berkarir di jalur musik hip-hop yang berakar kuat 
pada kelompok keturunan ras Afrika-Amerika (black), dan berhasil menembus pasar Amerika Serikat yang didominasi oleh ras kaukasian (white). Penelitian ini bertujuan untuk menjawab bagaimana representasi yang dilakukan oleh Rich Brian, seseorang yang tidak berasal dari kedua ras tersebut, dalam karya-karyanya yang mencerminkan identitas yang Brian miliki.

Melalui teori identitas sosial yang dikemukakan oleh Tajfel \& Turner dalam Baron \& Branscombe (2012) identitas merupakan sebuah kontinum yang terdiri dari ujung identitas pribadi dan ujung lainnya yaitu identitas sosial. Di mana seseorang menempatkan diri mereka dalam kontinum tersebut merupakan bagian dari identitas yang saat itu menjadi fokus perhatian seseorang dan akan mempengaruhi bagaimana mereka memandang diri mereka sendiri dan merespons orang lain. Dalam penelitian ini, telah dijelaskan bahwa Rich Brian memosisikan dirinya sebagai bagian dari negara Indonesia, dan bagian dari ras Asia pada konteks yang lebih luas. Dalam perjalanan kariernya di Amerika Serikat sebagai seorang musisi, Brian memilih untuk tetap memosisikan diri dan tidak menutup-nutupi identitas sosialnya tersebut. Bagaimana Brian memosisikan dirinya dan menunjukkan identitasnya itu memengaruhi karya yang kemudian Brian buat sebagai seorang musisi. Hal ini ia tunjukkan melalui proses representasi.

Representasi yang dimaksud oleh Hall (1997) pada teori Circuit of Culture yang ia kemukakan adalah cara seseorang dalam mengonstruksikan makna yang dipengaruhi oleh penggunaan tanda dan bahasa. Proses ini jika digabungkan dengan tahapan lainnya dalam sirkuit (produksi, konsumsi, regulasi, dan identitas) akan menciptakan sebuah budaya yang memengaruhi cara seorang individu dari sebuah kelompok bertindak dan mengonstruksi sebuah makna. Proses konstruksi makna dan pembangunan budaya ini saling memengaruhi satu sama lain dan berkelanjutan sehingga dibentuk ke dalam sebuah bentuk sirkuit.

Pada bagian pembahasan telah dijelaskan mengenai makna dari lirik lagu-lagu Rich Brian yang menyinggung identitasnya sebagai warga negara Indonesia atau bagian dari ras Asia. Penyebutan identitas tersebut Brian lakukan baik secara eksplisit maupun implisit melalui perantara simbol seperti bendera yang merupakan isyarat visual. Brian menggunakan bahasa Inggris sebagai perantara untuk mengkomunikasikan karyanya, sebuah bahasa dengan jumlah penutur terbanyak di dunia jika menggabungkan penutur asli (native speaker) dan bukan penutur asli (non-native speaker) (Eberhard, Simons, \& Fennig, 2020). Selain itu, lagu-lagu Rich Brian tergolong ke dalam genre hip-hop yang kini menjadi genre musik paling diminati oleh pasar Amerika Serikat. Bergabungnya Brian ke label musik 88Rising yang berfokus pada artis keturunan Asia yang memproduksi musik dengan genre hip-hop juga merupakan satu langkah penting yang mendukung keberhasilan Brian di skena musik hip-hop.

Tema-tema yang Brian bawa dalam lagulagunya tidak hanya menunjukkan identitas Brian semata, namun juga mengenai bagaimana stereotip yang melekat pada kelompok ras Asia yang tergolong minoritas di Amerika Serikat. Stereotip tersebut mencakup yellow peril/yellow 
skinned dan minoritas teladan. Asosiasi dari stereotip tersebut tidak bisa digolongkan pada sesuatu yang positif karena memiliki landasan rasisme struktural. Oleh karena itu, Brian juga mengkritisi stereotip ini melalui lirik lagu yang ia ciptakan.

\section{Penutup}

Dengan identitasnya sebagai warga negara Indonesia dan bagian dari ras Asia, Rich Brian membawa nama Indonesia dan Asia ke dunia industri musik global melalui penitian karier musik aliran hip-hop di Amerika Serikat. Meskipun Brian tidak langsung mengubah representasi ras Asia di kancah internasional, apa yang ia lakukan merupakan sebuah langkah yang berarti bagi orang-orang Asia lainnya. Di awal karirnya Brian sempat mengalami kontroversi, namun kini popularitasnya melejit dengan karya-karya yang berhasil menembus pasar Amerika Serikat dengan membawa genre musik hip-hop. Penelitian ini telah mengidentifikasi bagaimana Brian merepresentasikan identitas kewarganegaraan maupun rasnya melalui lirik lagu-lagu yang ia ciptakan pada dua album yang telah ia rilis sampai saat ini. Brian memosisikan dirinya di spektrum identitas secara sosial pada lirik lagunya dan ia tidak menutup-nutupi identitas tersebut. Representasi identitas ini Brian lakukan baik secara eksplisit maupun implisit, dengan perantara bahasa Inggris yang dipahami oleh mayoritas.

Penelitian ini terbatas hanya meneliti kepada lirik lagu sebagai perantara pengkomunikasian makna representasi identitas.
Bagi peneliti selanjutnya yang ingin melanjutkan penelitian ini, diharapkan dapat melengkapinya dengan bahasa visual seperti foto atau video klip. Atau, peneliti selanjutnya juga dapat mengeksplorasi tahapan lain dari sirkuit kultural selain representasi dan identitas yang telah dijelaskan dalam penelitian ini. Hal ini dimaksudkan untuk memperkaya pemahaman mengenai konstruksi makna dan budaya di dalam masyarakat.

\section{Daftar Pustaka}

Agato, Y. (2019, August 15). Rich Brian on His Growth, Dreams, and Asian Identity. Diambil kembali dari Vice ID: https://www.vice.com/en_asia/article/e vj4wp/rich-brian-on-his-growth-dreamsand-asian-identity

Andrew, D. (2018). Konstruksi Image Rich Chigga di Media Sosial dan Media Online. Jurnal EKomunikasi Program Studi IImu Komunikasi Universitas Kristen Petra, 6(1), 1-8.

Barker, C. (2000). Cultural Studies: Theory and Practice. SAGE.

Baron, R. A., \& Branscombe, N. R. (2012). Social Psychology: 13th Edition. New Jersey: Pearson Education, Inc.

Behm-Morawitz, E., \& Ortiz, M. (2012). Race, Ethnicity, and the Media. Dalam K. E. Dill, The Oxford Handbook of Media Psychology (hal. 307-324). New York: Oxford University Press.

BPS. (2010). Kewarganegaraan, Suku Bangsa, Agama, dan Bahasa Sehari-hari Penduduk Indonesia. Jakarta: Badan Pusat Statistik.

Chang, R. S. (2013). The Invention of Asian Americans. UC Irvine L. Review, 947.

Childs, D. (2015). Socially Constructing Race and History: Exploring Black Identity and Popular Culture in Social Studies Classrooms through Cultural Studies 
Framework. Journal of Pan African Studies, 55-73.

Chua, B. H., \& Cho, Y. (2012). Editorial introduction: American pop culture. Inter-Asia Cultural Studies, 485-494.

Colby, S. L., \& Ortman, J. M. (2015). Projections of the Size and Composition of The U.S. Population: 2014 to 2060. United States Census Bureau.

Cordington, R. (2003). Hip-Hop: The Culture, the Sound, the Science (Review of One Planet under a Groove: Hip-Hop and Contemporary Art. JSTOR : American Anthropological Association, 153-156.

Curtin, P. A., \& Gaither, T. K. (2005). Privileging Identity ,Difference, and Power: The Circuit of Culture As a Basis for Public Relations Theory. journal of Public Relation Research, 91-115.

Dao, D. Q. (2019, June 03). How 88Rising Raised the Bar for Asian Representation. Diambil kembali dari Paper.

Dasfriana, D. A. (2019). Komodifikasi dan Universalisme Budaya dalam Asian Hiphop di Amerika Serikat oleh 88Rising. Skripsi Program Studi Hubungan Internasional Fakultas IImu Sosial dan IImu Politik Universitas Katolik Parahyangan.

Diep, E. (2019, June 26). Rich Brian Returns With "Yellow" and Talks New Album 'The Sailor'. Diambil kembali dari Complex: https://www.complex.com/music/2019/ 06/rich-brian-interview-yellow-thesailor

Dirlik, A. (2003). Global Modernity? Modernity In An Age of Global Capitalism. European Journal of Social Theory, 6(3), 275-292.

du Gay, P., Hall, S., Janes, L., Mackay, H., \& Negus, K. (1997). Doing Cultural Studies: The Story of Walkman. Glasgow: Bath PRess Colourbooks.

Eberhard, D. M., Simons, G. F., \& Fennig, C. D. (2020). Ethnologue: Languages of the World. Twenty-third edition. Dallas, Texas: SIL International. Dipetik June 8, 2020 , $\mathrm{d}$ a $\mathrm{r} \mathrm{i}$ https://www.ethnologue.com/guides/m ost-spoken-languages

Ferguson, M. (2005). The Mythology about Globalization. Dalam D. McQuail, D. McQuail, P. Golding, \& E. D. Bens (Penyunt.), Communication Theory and Research (hal. 23-35). London: SAGE Publications Ltd.

Geeting, D. B. (2018, February 1). Rich Brian Discusses Debut Album 'Amen' and Name Change: 'Rich Chigga Isn't Me Anymore'. Diambil kembali dari B i l l b 0 a $r$ d : https://www.billboard.com/articles/colu mns/hip-hop/8097424/rich-brianinterview-album-amen-name-change

Gelfland, Z. (2017, July 18). Rapper Rich Chigga on Power of Social Media, His Idol Donald Glover. Dipetik May 7, 2020, dari Rolling $\mathrm{s} \quad \mathrm{t} \quad \mathrm{o} \quad \mathrm{n}$ e https://www.rollingstone.com/music/m usic-features/rapper-rich-chigga-onpower-of-social-media-his-idol-donaldglover-206055/

Hall, S. (1997). The Work of Representation. Dalam S. Hall, Representation: Cultural Representation and Signifying Practices (hal. 13-74). London: The Open University and SAGE Publicdtions Ltd.

Herd, M. (2016, November 24). Rhymes of Brian: Jakarta's Rich Chigga is a home-schooled, hip-hop sensation. Dipetik May 7, 2020, d a ri The Guardian : https://www.theguardian.com/cities/20 $16 /$ nov/24/rhymes-brian-imanueljakarta-rich-chigga-home-schooled-hiphop-sensation

Husen, W. (2018, February 2). Rich Brian Croons 'Late Late Show' With a Stripped-Down Medley of 'Amen' and 'Cold'. Dipetik May 7, $2020, d a r i$ Bill board: https://www.billboard.com/articles/colu mns/hip-hop/8097789/rich-brian-amencold-performance-late-late-show-jamescorden-video

Iwabuchi, K. (2010). Globalization, East Asian Media Cultures, and Their Publics. Asian Journal of Communication, 197-212.

Kawai, Y. (2005). Stereotyping Asian Americans: 
The Dialectic of the Model Minority and the Yellow Peril. Howard Journal of Communications, 16(1).

Kim, C. J. (1999). The racial triangulation of Asian Americans. Politics \& society, 105-138.

Kim, Y. (2013). Representation of People of Asian Descent in Mainstream Mass Media within the United States. Multicultural Education Review, 20-48.

Leve, A. M. (2012). The Circuit of Culture as a generative tool of contemporary analysis: Examining the construction of an education commodity. Joint AARE APERA International Conference, Sydney 2012, 1-12.

Lightman, E. J., McCarthy, P. M., Dufty, D. F., \& McNamara, D. S. (2007). Using computational text analysis tools to compare the lyrics of suicidal and nonsuicidal songwriters. Proceedings of the Annual Meeting of the Cognitive Science Society.

Lin, G. (2009). Higher Education Research Methodology-Literature Method. International Education Studies, 2(4), 179-181.

LulI, J. (2001). Superculture for The Communication Age. Dalam J. Lull, Culture In The Communication (hal. 132164). New York: Taylor \& Francis eLibrary.

Lynch, J. (2018, January 5). For the first time in history, hip-hop has surpassed rock to become the most popular music genre, according to Nielsen. Dipetik March 24, $2020, \mathrm{~d}$ a r i B I o o m b e r g: https://www.businessinsider.com/hiphop-passes-rock-most-popular-musicgenre-nielsen-2018-1 ? IR=T

Oloka-Onyango, J. (2005, November). Who's Watching "Big Brother"? Globalization and the Protection of Cultural Rights in Present Day Africa. Human Rights Quarterly, 27(4), 1245-1273.

O'Reilly, D. (2010). Cultural Brands/Branding Cultures. Journal Of Marketing Management, 573-588.

Pasha, A. R. (2019, September 24). Rich Brian Awali
Karir dari Cover Lagu Rap, Kini Jadi Rapper Sukses. Dipetik May 7, 2020, dari c e $r \quad m$ a $t i$. c $\quad$ o $m$ : https://www.cermati.com/artikel/richbrian-awali-karir-dari-cover-lagu-rapkini-jadi-rapper-sukses

Pettijohn, T. F., \& Sacco Jr, D. F. (2009). The language of lyrics: An analysis of popular Billboard songs across conditions of social and economic threat. Journal of Language and Social Psychology, 297-311.

Real, M. (2001). Cultural Theory in Popular Culture and Media Spectacles. Dalam J. Lull, Culture in The Communication Age (hal. 167-178). London: Routledge.

Reyes, A. (2017). Language, identity, and stereotype among Southeast Asian American youth: The other Asian. Routledge.

Saputri, K. (2018, February 13). Delegasi Indonesia Siap Tampil di Festival SXSW 2018. Dipetik March 24, 2020, dari Badan Ekonomi Kreatif Indonesia: https://www.bekraf.go.id/berita/page/8 /delegasi-indonesia-siap-tampil-difestival-sxsw-2018

Schatz, R. T., \& Lavine, H. (2007). Waving the Flag: National Symbolism, Social Identity and Political Engagement. Political Psychology, 329-355.

Setaro, S. (2018, February 2). Exclusive: Rich Brian on His Controversial Past and What to Expect From Debut Album 'Amen'. Diambil kembali dari Complex: https://www.complex.com/music/2018 /02/rich-brian-interview

Sparks, C. (2007). Globalization, Development, and The Mass Media. London: SAGE Publications Ltd.

Spurgin, K. M., \& Wildemuth, B. M. (2017). Content Analysis. Dalam B. M. Wildemuth, Applications of Social Research Methods To Questions In Information and Library Science (hal. 298). Westport: Greenwood Publishing Group, Inc.

Staple, J. (2016, October 14). 18 Million Views and Counting: Rich Chigga Talks Going Global and His New Friend Ghostface. Dipetik 
May 7, 2020, dari Vice US: https://www.vice.com/en_us/article/mv b7j3/18-million-views-and-countingrich-chigga-talks-going-global-and-hisnew-friend-ghostface

Tombleson, B., \& Wolf, K. (2017). Rethinking the circuit of culture: How participatory culture has transformed cross-cultural communication. Public Relations Review, 14-25.

van der Meer, G. (2008). On Connotation, Denotation and All That, or: Why a Nigger Is Not a-Black Person. Proceedings of the XIII EURALEX International Congress, 1547-1555.

Wong, A. (2018, February 2). Rich Brian Learned How to Rap from YouTube. Dipetik April $06, \quad 2020, \quad d$ a $\mathrm{i} \quad \mathrm{GQ}$ : https://www.gq.com/story/rich-brianamen-interview

Woodward, K. (1997). Concepts of identity and difference. Dalam K. Woodward, Identity and difference (hal. 7-50). Thousand Oaks: SAGE.

Wu, C. (2018, April 30). Q\&AA: 88RISING'S SEAN MIYASHIRO WANTS TO BUILD 'DISNEY FOR ASIAN CULTURE'. Dipetik March 22, $2020, \quad d a r i \quad A d A g e$ : https://adage.com/article/qaa/q-aa88rising-s-sean-miyshiro/313297

Xu, J., \& Lee, J. C. (2013). The marginalized "model" minority: An empirical examination of the racial triangulation of Asian Americans. Social Forces, 1363-1397.

Zhang, Q. (2010). Asian Americans Beyond the Model Minority Stereotype: The Nerdy and the Left Out. Journal of International and Intercultural Communication, 20-37.

Zhang, Y., \& Wildemuth, B. M. (2017). Content Analysis. Dalam B. M. Wildemuth, Applications of Social Research Methods To Questions In Information and Library Science (hal. 308-309). Westport: Greenwood Publishing Group, Inc. 